the study of the biochemistry of vegetables were shown, and this technique is being used in an investigation of a virus inhibitor present in rhubarb sap. A soil map of the Station's 280 acres was on view together with soil monoliths.

The Irrigation Section demonstrated the water-loss by transpiration and evaporation from cauliflowers during bright sunshine and showed that it was equivalent to about 200 gallons an hour per acre of growing crop. Different soil moisture meters were displayed together with data on their performance, and a prototype gauge was shown which indicated the minimum amount of water required to bring soil under a crop to field capacity ; this gauge takes into account rainfall and water loss by transpiration and evaporation. The accuracy and efficiency of various techniques for measurement of leaf area were demonstrated, and the effects of different soil moisture conditions on growth, yield and quality of vegetables were shown.

The Entomology Section showed the life-cycle of the cabbage root fly, the damage it causes to brassica crops, and the most effective methods of controlling it. Illustrations were given of some natural predators of the pest and of insecticidal treatments which may destroy the predators, thus leaving a clear field for severe attack by the pest. The biology of the carrot fly, a serious pest of carrots, parsnips and parsley, was shown together with methods of insecticidal control involving seed dressings followed sometimes by supplementary sprays. A tasting panel assesses the degree of taint or off-flavour of carrots which may be brought about by certain insecticidal treatments. The life-history of the pea moth and the per aphid and their control by DDT were demonstrated. Work in progress on the biology and control of lettuce root aphid was shown; but the recent discovery of varieties resistant to attack appears to offer the best solution of the problem.

The Pathology Section illustrated the life-history of the fungus which causes crook root disease of watercress, and the promising results obtained for the control of the disease by adding to the cress beds material which liberates minute quantities of zinc. It also showed the life-history of the bacterial pathogen found to cause the silvering disease of red beet seed crops, and the degree of control obtained by seed treatment with streptomycin. Methods of eliminating sources of infection by the fungus Didymella on outdoor tomato crops, and the effects of fungicides in checking the spread of the disease were exhibited. Parsnip canker has been found not to be invariably associated with damage by carrot fly larvae, and a fungus which can cause the disease has been isolated. Work in progress on virus diseases of rhubarb and watercress was exhibited, also some varieties of mint found to have resistance to mint rust. Results of studies on the control of Botrytis in lettuce by cul. tural methods and by fungicides were also shown.

The Weeds Section demonstrated techniques used in its ecological studies which are providing fundamental information necessary for the development of weed control in vegetable crops by cultural and chemical means. Changes in weed populations brought about by different manurial, cultivation and rotation treatments were described, and the effects of competition between weeds and vegetable crops at different stages of growth were shown. A demonstra. tion was given of the effects of dinoseb (ammonium), dinoseb (amine), and a substituted phenoxybutyric acid MCPB as herbicides for market garden peas, also the degree of tolerance of different varieties to the sprays. The residual pre-emergence herbicide CMU was shown also to be useful for the control of annual weeds in asparagus beds.

The Statistics Section carries out investigations with the object of improving the efficiency of field experiments with vegetables, in addition to its advisory work for other Sections and for outside bodies on the design and analysis of experiments. In studies on the origin of experimental errors in the field, the effects of different methods of sowing peas, and of using different size grades of cauliflower plants when planting in the field were demonstrated. The economics of spacing of glasshouse and frame lettuce were illustrated, and work in progress was shown on the genetics of continuous variation in French beans.

J. Phil

\section{NOCTURNAL TEMPERATURE PROFILE ABOVE BARE SOIL ON CLEAR NIGHTS}

T has long been established that in the lowest few 1 hundred feet of the atmosphere there is on calm clear nights on the whole an inversion (that is, temperature increases with height), presumably determined by radiation of heat from the ground. The observations of Johnson and Heywood at Leafield (Meteorological Office Geophysical Memoir 77 ; 1938) showed that this inversion comes into being remarkably suddenly about sunset. As part of this structure it was supposed that the lowest temperature was normally to be found on the ground surface itself, the air above being cooled by loss of heat to the ground by conduction and convection. Doubts as to whether this was always so have been expressed for a long time. J. Glaisher in 1847 reported that on all clear nights in the year 1843-44 the mean minimum temperature on short grass was $0.8 \mathrm{deg}$. F. higher than that recorded 1 in. above the top of the grass. Many other workers have found the tempera. ture on radiation nights to be sometimes lower a few inches above the surface than on the surface; but such a structure has not been regarded by meteorologists as a regular feature.

J. V. Lake, of the University of Reading, has recently described in the Quarterly Journal of the Royal Meteorological Society (April 1956) the results of temperature observations with the most up-to-date instruments in the lowest few feet over bare soil on calm clear nights. Lake measured temperatures with both minute thermistor beads and with ordinary unscreened alcohol-in-glass minimum thermometers at heights of $0 \cdot 1,0 \cdot 5,1 \cdot 5,2 \cdot 5,3.5$ and 54 in. The results were all the same: minimum temperature at $2-3$ in. above the surfare, with an inversion above and a super adiabatic lapse-rate below. For completeness the surface radiation temperature was measured with a spirit thermometer. On the early morning of March 22, 1955, the surface radiation temperature was $21^{\circ} \mathrm{F}$, and the temperatures at the higher levels specified above were, in the mean of fifty-two observations at each height, respectively : $18 \cdot 6,17 \cdot 3,16 \cdot 6,16 \cdot 4,16 \cdot 8$ and $18 \cdot 4^{\circ} \mathrm{F}$. The standard deviations of the observations were 0.93 deg. F. at $0 \cdot 1 \mathrm{in}$. and $0 \cdot 35-0 \cdot 46 \mathrm{deg}$. F. at higher levels.

The temperature profile below the minimum is of the kind which occurs over a surface strongly heated 
by sunshine having a lapse-rate more than a thousand times the value of the dry adiabatic lapse-rate (1 deg. F./2,187 in.) and even hundreds of times the so-called 'auto-convective' lapse-rate (1 deg. F.l 640 in.) at which the density of the air increases upwards. As a by-product of the investigation, it was found that the reduction of surface temperature below the value at sunset was proportional to the square root of the time, in agreement with Brunt's theory of surface-temperature changes on radiation nights, which takes no account of interchange of heat between air and ground and balances radiation loss from the ground against conduction of heat upwards in the soil. The observations were made under dead calm conditions over a level field at a point 100 yards from the nearest boundary, so that vitiation by horizontal influx of colder air seems to be ruled out, and $\mathrm{Mr}$. Lake shows that instrumental errors cannot account for the profiles.

The detailed physical reason for the profile is still obscure. It appears that the air near the ground under calm conditions loses heat by radiation rather than by convection and conduction until a state of radiative equilibrium is reached depending on the water vapour content. The fact that the variation of the surface minimum temperature agreed well with Brunt's theory supports this. It is very desirable, because of the great importance of accurate forecasting of minimum temperatures for agricultural purposes and for general scientific reasons, that an adequate physical theory of the temperature distribution in the lowest foot of the air on radiation nights should be found.

\section{THE CAPERCAILZIE}

A $N$ account of the feeding habits and breeding behaviour of the capercailzie has been set out in No. 37 of the Forestry Commission's admirable leaflets. The capercailzie well merited the delightful names by which it was known in medieval timescock of the woods, horse of the woods, avercalzie, auercalze, wild peacock, wild turkey-for the cock caper is one of the finest game-birds in Europe. In the British Isles, it is found only in the woods and forests of Scotland.

The cock bird is about a yard in length, with the hen capercailzie a foot shorter. Originally, the capercailzie was found in England, Wales and Ireland, as well as Scotland; in England the birds became extinct around 1660-70. In Scotland, the last two positive references to truly native birds seem to be those from the Abernethy and Glenmoriston districts in 1771 . The capercailzies present in Scottish woods and forests to-day owe their presence to an introduction of Swedish birds, made in 1837. Then, Lord Breadalbane imported thirteen cocks and nineteen hens and turned them out on his estate at Taymouth Castle, near Aberfeldy, in Perthshire. Unlike previous introductions elsewhere, this one was so successful that after twenty-five years there were more than a thousand birds present on this estate alone.

The typical habitat of the capercailzie consists of hillsides with woods of mature Scots pine. Capercailzie appear to be invading Forestry Commission plantations of Scots pine, larch and spruce when these reach a height of about twenty-five feet.

In winter, the capercailzie's food includes the shoots, buds, leaves, seeds and young cones of the
Scots pine, and occasionally those of other conifers. These, however, form only a small proportion of its total food supply, and where only relatively small numbers of capercailzies are found amid middleaged or maturing pinewoods, little serious economic damage results. The position may be very different in young, newly established plantations, particularly where these lie close to older woods with a heavy stocking of capercailzies. These birds find the winter buds and growing shoots of the young pines very palatable, and all too often they peck out the leading bud, thus causing serious loss of annual growth, and perhaps a distorted stem. Further damage may be done because of the bird's weight; if it settles on a side branch this may break away from the main stem, causing a serious wound to the tree.

Whether or not control measures are necessary depends on local circumstances. In the older woods, the harm the capercailzie does is negligible. Under other conditions, for example, where the felling of mature woods has driven the birds to take refuge in young plantations, it may be necessary to restrict the numbers of the birds in order to avoid serious loss of timber production. Control is commonly effected by shooting, which, owing to the bird's large size and conspicuous appearance, presents no particular difficulties. Provided it does not become unduly numerous in the younger plantations, this interesting and beautiful bird may be tolerated and even encouraged.

\section{FAT FORMATION IN A DIATOM}

7 HE photosynthesis and formation of fats in a diatom, Navicula pelliculosa, using carbon-14 as a tracer, has been investigated in some detail by G. E. Fogg (Ann. Bot., N.S. 20, 78, 265 ; 1956). Fixation into the following cell fractions was determined: (A) material soluble in 80 per cent ethanol but insoluble in benzene; $(B)$ material soluble both in 80 per cent ethanol and in benzene; $(C)$ material insoluble in 80 per cent ethanol. Carbon fixed in photosynthesis was incorporated, rapidly and in amounts representing up to 70 per cent of the total fixation, into fractions $B$ and $C$, as well as into fraction $A$. Considerable variation was found in the proportions of carbon entering the three fractions in the light; in actively growing cells the proportion entering fraction $C$ preponderated over that in $B$, corresponding to the synthesis of protein, whereas in nitrogen-deficient cells fixation in $B$ was the greater, corresponding to the synthesis of fat.

These patterns changed only slowly, over periods of days, following the transfer of cells to altered conditions of nitrate supply. However, when ammonium nitrogen was supplied to nitrogen-deficient cells a marked change in distribution of carbon fixed occurred within 5 min., fixation in fraction $B$ falling to a low value and that in $A$ rising correspondingly. In eells subjected to prolonged nitrogen-deficiency, fixation in fraction $B$ fell to a relatively low value; but the proportion which this fraction formed of the total dry matter in the cells rose as a result of an increased rate of loss from the cells of constituents other than lipides. The distribution of carbon fixed was also dependent on light intensity. Fixation in fractions $B$ and $C$ rose relatively to that in $A$ as light intensity was increased up to 100 footcandles but fell again at the highest intensity used, 2,000 foot-candles. 